
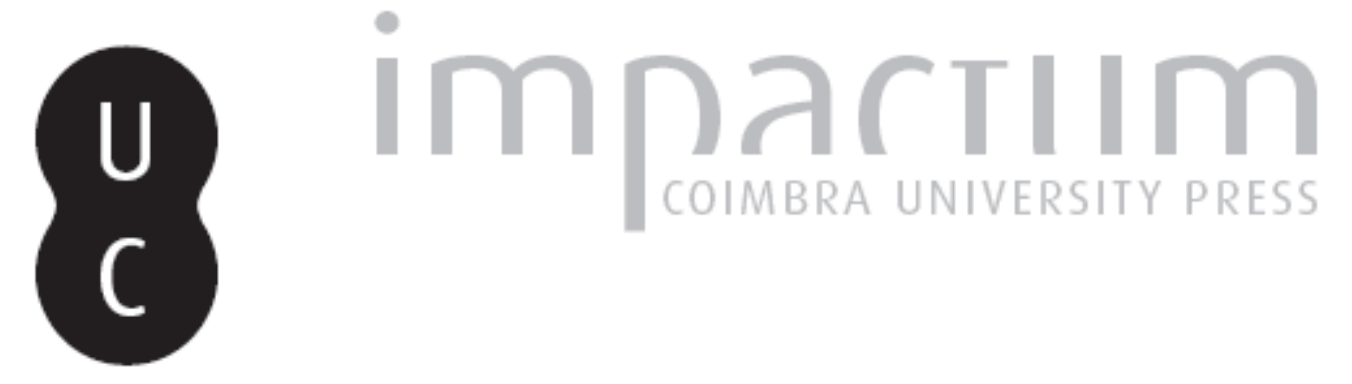

Observações sobre a ocupação de época romana no Vale do Mira

Autor(es): $\quad$ Correia, Virgílio Hipólito

Publicado por: Faculdade de Letras da Universidade de Coimbra

URL persistente:

URI:http://hdl.handle.net/10316.2/39129

DOI:

DOI:http://dx.doi.org/10.14195/1647-8657_54_6

Accessed : $\quad$ 26-Apr-2023 13:39:34

A navegação consulta e descarregamento dos títulos inseridos nas Bibliotecas Digitais UC Digitalis, UC Pombalina e UC Impactum, pressupõem a aceitação plena e sem reservas dos Termos e Condições de Uso destas Bibliotecas Digitais, disponíveis em https://digitalis.uc.pt/pt-pt/termos.

Conforme exposto nos referidos Termos e Condições de Uso, o descarregamento de títulos de acesso restrito requer uma licença válida de autorização devendo o utilizador aceder ao(s) documento(s) a partir de um endereço de IP da instituição detentora da supramencionada licença.

Ao utilizador é apenas permitido o descarregamento para uso pessoal, pelo que o emprego do(s) título(s) descarregado(s) para outro fim, designadamente comercial, carece de autorização do respetivo autor ou editor da obra.

Na medida em que todas as obras da UC Digitalis se encontram protegidas pelo Código do Direito de Autor e Direitos Conexos e demais legislação aplicável, toda a cópia, parcial ou total, deste documento, nos casos em que é legalmente admitida, deverá conter ou fazer-se acompanhar por este aviso. 
CONIMBRIGA

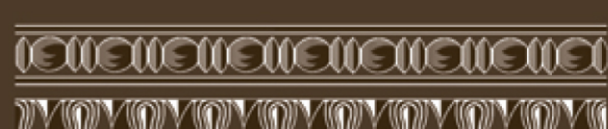

WN N N N

INSTITUTO DE ARQUEOLOGIA

VOLUME LIV • 2015

FACULDADE DE LETRAS 


\author{
VIRGílio HiPólito CORREIA \\ Museu Monográfico de Conimbriga. Faculdade de Letras da Universidade do Porto. \\ Centro de Estudos de Arqueologia Artes e Ciências do Património \\ vrglcorreia@gmail.com
}

\title{
OBSERVAÇÕES SOBRE A OCUPAÇÃO DE ÉPOCA ROMANA NO VALE DO MIRA
}

\author{
OBSERVATIONS ON THE ROMAN OCCUPATION \\ OF THE VALLEY OF THE MIRA \\ "Conimbriga" LIV (2015) p. 157-178
}

http://dx.doi.org/10.14195/1647-8657 54_6

RESUMO: É apresentada uma abordagem integrada dos dados disponíveis sobre a ocupação romana no vale do Rio Mira (Alentejo, Portugal), de que a escassez é interpretada, não como produto de insuficiente investigação, mas como uma situação decorrente de um percurso histórico concreto aí ocorrido; é a este propósito discutida a situação da Arandis romana, para a qual é proposta uma localização (Castro da Cola, Ourique), baseada em argumentos arqueológicos e linguísticos e toponomásticos.

A originalidade da ocupação romana da área e as raízes históricas da situação são discutidas desde um ponto de vista teórico e antropológico, recorrendo a conceitos do domínio da arqueologia da paisagem.

PALAVRAS-ChaVE: Lusitânia; Romanização; Arandis; Rio Mira; Arqueologia da paisagem

AbSTRACT: An integrated approach to available data on the Roman occupation of the Mira River Valley (Alentejo, Portugal) is presented; the scarcity thereof is interpreted as a situation arising from the

Conimbriga, 54 (2015) 157-178 
concrete historical path taken, rather than the product of insufficient research. In this context the situation of the Roman town of Arandis is discussed, and its location proposed at the so-called Castro da Cola (Ourique), on the basis of archaeological arguments and the linguistics of the place-name.

The originality of the Roman occupation of the area and the historical roots of the situation are discussed from a theoretical and anthropological point of view, using concepts from landscape archeology.

Keywords: Lusitania; Romanization; Arandis; River Mira; Landscape archaeology 


\section{OBSERVAÇÕES SOBRE A OCUPAÇÃO DE ÉPOCA ROMANA NO VALE DO MIRA}

\section{Um problema de geografia antiga regional}

A ocupação de época romana imperial na bacia do Mira e do Alto Sado $^{1}$ e zonas serranas adjacentes é quase inexistente. Este facto é surpreendente, paradoxal mesmo, no âmbito do Sudoeste da península Ibérica.

Designadamente naqueles elementos do registo arqueológico que se associam ao desenvolvimento de uma civilização urbana como é a romana, os actuais concelhos de Odemira, Ourique e Almodôvar destacam-se, em qualquer análise, pela ausência de vestígios. Com efeito, só na zona de Garvão e Panóias (conc. Ourique) se verifica uma maior densidade de vestígios, explicável sem dúvida, tal como a concentração de sítios e achados nos arredores da Messejana (conc. Aljustrel), pelo desenvolvimento de uma zona de exploração agrícola intensiva na dependência de Vipasca, mas, para além disto, em toda a restante vasta área, são contados os sítios arqueológicos (Alarcão 1988, vol. 2, fasc., 3, fl. 7 e 8), não se conhece qualquer elemento de escultura (Sousa 1990, passim), está identificado um único local com mosaicos (Oleiro 1986: 112-113) e, no que diz respeito a um dos principais elementos associados à vida pública - a epigrafia (Susini 1968: 72-83) - contam-se apenas 6 inscrições (Encarnação 1984, nº 120, 124, 126, 129, 139 e

\footnotetext{
${ }^{1} \mathrm{O}$ presente texto nasceu de uma intervenção impromptu no colóquio "Ignorância e Esquecimento" organizado pela Câmara Municipal de Odemira em 12-13 de Abril de 2013, ulteriormente reduzida a escrito, desenvolvida e preparada para uma publicação em atas que até agora não viram a luz. São devidos agradecimentos ao organizador do colóquio, Pedro Prista, e a Jorge Vilhena.

Este texto beneficiou dos comentários dos revisores anónimos. Os erros subsistentes são da responsabilidade do autor.
}

Conimbriga, 54 (2015) 157-178 
140), todas de carácter funerário e tendo como característica comum os formulários lacónicos escolhidos.

Este elemento epigráfico merece um aprofundamento, pois permite caracterizar adequadamente a situação global da ocupação imperial romana na zona: trata-se de uma área de cerca de $3000 \mathrm{~km} 2$, suficiente para acomodar de duas a cinco vezes o território da capital da província, Emerita Augusta (conforme se considerem as propostas de RoDRíGUEZ 2010: 133 ou de CerRILlo et al. 1990: 65), onde se conhece um número de epígrafes apenas vestigial frente à quantidade conhecida em qualquer uma das civitates vizinhas (Cilpes: 16; Balsa: 18; Myrtillis: 25; Ossonoba: 36; Mirobriga: 37; Salacia cum Caetobriga: 45; Pax Iulia: 98. Cf. Encarnação 1984, passim - haverá atualizações a fazer na contagem).

Acresce o argumento forte de que, aqui, não estamos perante um défice de informação devido à falta de investigação pois, por contraste, a epigrafia da Idade do Ferro na mesma zona é muito bem conhecida e, enquanto o seu inventário tem continuado a crescer de maneira assinalável (CORREIA 2009b; Melro et al. 2009), o corpus da epigrafia romana mantém-se na mesma dimensão desde a publicação fundadora de J. d'Encarnação e, nas duas últimas décadas, entre as quase quinhentas inscrições publicadas no "Ficheiro Epigráfico" (suplemento da revista Conimbriga, do Instituto de Arqueologia da Faculdade de Letras da Universidade de Coimbra, dirigida desde 1982 pelo referido epigrafista), nem uma só nova inscrição romana dos três concelhos envolvidos foi publicada.

O vácuo não é, portanto, aparente, é um vácuo real de evidências em sentido lato, e de uma ocupação de base urbana, romana stricto senso. Este facto tem sido insuficientemente apreciado na bibliografia.

Este problema, que parece claríssimo no que à ocupação de tipo urbano diz respeito, reflete-se também no aspeto da ocupação rural (CURCHIN 1991: 125-129), mas com matizes.

A área em causa não foi objeto de prospeções especiais desde a presença na região de Abel Viana (que todavia foi de relevo; OliveIRA 1984: 200-207, faz vinte e duas entradas de trabalhos do autor na região, que representam um número ainda superior de artigos, já que alguns deles faziam parte de séries, designadamente publicadas no Arquivo de Beja); o facto reflete-se em que, nos sítios referenciados em Roman Portugal nos três concelhos envolvidos (Alarcão 1988, II-3: 179-180), num total de vinte e um, oito correspondem a locais de achado de inscrições funerárias e os restantes treze, nenhum deles 
escavado, incluem ainda Odemira, Garvão e Vila Nova de Milfontes, nenhum deles sítios rurais romanos stricto senso. Restam portanto dez sítios rurais romanos de época possivelmente imperial, como representantes optimo iure desse tipo de povoamento. Mas aplica-se aqui o mesmo raciocínio que a propósito da epigrafia: existem trabalhos arqueológicos na zona que revelam o padrão de povoamento noutras épocas, designadamente durante a Idade do Ferro (CorReia 1993: 353) e, se os sítios romanos fossem reconhecivelmente (i.e. de tipo e aspeto semelhante aos reconhecidos noutras zonas) abundantes, eles não deixariam de ter sido recenseados.

Um défice de investigação na região existe. É a este propósito eloquente o facto de a ocupação romana de Vila Nova de Milfontes (Correia 1985: 9; Alarcão 1988: 179 n 7/42A; Vilhena 2013: 26-29; id. n. p.), não ter sido alvo de indagação específica num trabalho que não deveria ter deixado de a considerar (BLOT 2003: 269-272), mas essa explicação é de curto espectro no tratamento da verdadeira natureza da ocupação rural romana de época imperial na região (cf. ATtema e SchÖRnER 2012, passim) que, certamente não de forma absoluta mas devido à capacidade da investigação, no estado atual dos conhecimentos e com as ferramentas conceptuais existentes (e mesmo recorrendo ao conceito de civitas sine urbs; Mangas 2014: 814-826) vê a região como um vácuo.

Neste vácuo existe um ponto problemático, que é a civitas dos Aranditani referida por Plínio, Nat. Hist. IV-118, cuja sede é também referida por Ptolomeu, Geog. II-5, e, mais tarde, pelos Itinerários sob a forma de Arannis (AlarCão 1990: 23). Como a descrição das vias pertinentes é problemática, não é de surpreender que, no panorama acima descrito, a localização da mutatio que poderia corresponder à sede da civitas nunca tenha podido ser apontada com segurança (pace Bernardes 2006; Ponte 2012).

Um exame aprofundado da problemática da rede viária (MANTAS 2012: 207-208) permite, todavia esclarecer os aspectos obscuros das fontes itinerárias e fazer coincidir, ao nível apenas aproximativo que há obrigatoriamente que aceitar, as distâncias entre os locais referidos (cf. o caveat de CuRCHIN 2004: 110-112). Arandis situar-se-ia na região de Ourique. Cremos ser possível propor a sua localização:

- Desde David Lopes (1968: 127-128) que se aceita a localização em Nossa Senhora da Cola (já referida por ANDRÉ DE RESENDE; cf. FERNANDES 1996: 201-202) da sede do concelho medieval 
de Marachique (cf. Viana 1961: 62-88), testemunhada pela sobrevivência dos topónimos Marchica e Marchicão nas proximidades. Apesar das próprias hesitações do ilustre arabista (Lopes 1968: 155), é possível que o topónimo árabe esconda o pré-romano. Estando, em âmbito latino, o nome do lugar já em enfraquecimento, de Arandis para Aranis, este último teria sido arabizado pela prefixação da partícula que, em algumas formas verbais, forma o particípio não-agentivo ma- (CORRIENTE 1984: 167), e pelo sufixo -ique, que é bem conhecido na área (LOPES 1968, 156); com a elisão definitiva do elemento -nd- teríamos, portanto, *M(a)-Ara $(n[d] i)$ s-ique -> *Marasique.

Esta formação encontra paralelos, por exemplo, na formação a partir do topónimo do (Pagus) Gallo(rum), do moderno nome de Ma-Gallo-n, na província aragonesa de Saragoça (BuRILlo 1998: 176).

Jorge Alarcão (1985: 103-104) propôs para o problema de Arandis o conceito de "experiência urbana e administrativa falhada", partindo do princípio da distribuição regular das civitates romanas (cf. HODDER 1972) aplicado ao território nacional (grosso modo a Lusitânia ocidental), segundo os princípios de W. Christaller e a análise do "vizinho mais próximo" (polígonos de Thiessen; para a técnica, cf. Hodder e Hassall 1971). O determinismo do modelo é porventura questionável nos seus fundamentos de análise da "rede urbana" (RONCAYOLO 1986: 416-421) por ignorar elementos essenciais que distorcem essa "rede" (ETIENNE 1990: 215-231) e, por outro lado, a fonte pliniana, ou a intervenção do próprio autor sobre ela, demonstravelmente transformou numa enumeração monótona de circunscrições administrativas aquilo que seria certamente um panorama mais complexo de entidades de origem pré-romana, em devir sob a organização da província (GuERRA 1995: 105-15; AlARCÃo 1990: 30).

Neste sentido, talvez a experiência de Arandis não tenha falhado, mas não tenha nunca existido; o que terá falhado, na realidade, terá sido a experiência política necessariamente subjacente ao projecto urbano e administrativo. O que conhecemos da arqueologia da Cola (CORREIA 2002; VILHENA 2006) corresponde bem a esta reconstituição histórica; em qualquer caso, já não seria, nos nossos dias, expectável para as ruínas de Arandis uma importante estrutura monumental aguardando descoberta.

Importa olhar para as realidades urbanas subjacentes às referên- 
cias da enumeração pliniana para se compreender melhor o que o devir histórico de Arandis no período imperial (não) tenha sido.

Se nos ativermos ao extremo sul da Lusitânia, encontramos, na zona algarvia, o oppidum stipendiarium de Ossonoba, cidade de origem pré-romana com uma vasta chora que, aparentemente, se mantém nos seus limites, rodeada por duas áreas em que a situação é contrastante: a Oeste a civitas dos Cilibitani, que terá contado, em época imperial, com a contributio da Laccobriga e do Portus Hanibalis (povoações mencionadas por Pompónio Mela, De situ orbis, III-1-7, no território do promontorium sacrum; AlarCão 1992: 143) e da Ipses que conhecemos pela numismática (CORREIA 2004: 280-283; mas cf. AlarCÃo 2010); no outro extremo do Algarve, Baesuris (CORREIA 2004: 279-81) foi certamente localidade contributa de Balsa (MANTAS 1997: 293), sede dos Balsenses (cf. CIL II 5161; ENCARNAÇão 1984: 134-136, $\mathrm{n}^{\mathrm{o}} 80$ ).

Mais a norte, o Alentejo central mostra três grandes centros, todos com origem pré-romana - Salacia, Pax Iulia e Myrtillis - a que se adicionam alguns outros centros-satélite como Caetobriga, Mirobriga e Vipasca, também talvez como Sines. Estes dois eixos, a costa sul e o eixo Guadiana/Foz do Sado, enquadram a região dos Aranditani; são regiões distintas, com configurações histórico-arqueológicas reconhecidamente diversas, e é na especificidade do seu passado individual que se impõe buscar a explicação da formação histórico-geográfica única com que nos deparamos.

\section{As raízes do fenómeno}

O fenómeno dominante na ocupação proto-histórica do vale do Mira, muito em particular do seu troço médio, é o da existência de um padrão dual de povoamento, no qual coexistem povoados nucleados de certa dimensão, rodeados por necrópoles de vários tipos, e grandes edifícios, colocados em zonas estratégicas de exploração de recursos, que implantam de forma estratégica na sua proximidade as suas necrópoles monumentais (CORREIA 1995). Estas são-nos melhor conhecidas através da epigrafia, enquanto dos povoados, o melhor conhecido é o de Fernão Vaz (id. 2007; 2009a; com a bibliografia anterior). A generalidade dos indicadores arqueológicos parece mostrar que é nestes núcleos que reside uma parte substancial da capacidade económica (medida pelas 
importações conhecidas) e do domínio social (indicada pela capacidade de representação simbólica e de domínio ideológico que as epígrafes testemunham), sendo que a tensão certamente existente entre pólos de um e outro tipo se resolve, ao menos em alguns pontos, a partir do séc. V a.C., a favor dos povoados nucleados, como Garvão (Beirão et al. 1985; Correia 1996), Mesas do Castelinho (FABIÃo e GuerRa 2010; Guerra e Fabião 2010) ou a própria Odemira (VILHENA e Rodrigues 2009; VILHENA 2012).

Não parece sustentável a explicação dos fenómenos observados arqueologicamente através de narrativas de base étnica com configurações sucessivamente modificadas por migrações (ARRUDA et al. 1995, seguido em FABĩ̃o e Guerra 2010 e Guerra e FABião 2010), que não se atestam no registo arqueológico, não são claras no próprio registo literário antigo e que são, de facto, produto de uma corrente de pensamento que projecta as ideias próprias dos modernos estados-nação sobre a Antiguidade, sem grande consideração pelo que sabemos terem sido as formas próprias de auto-representação dos povos antigos (CORREIA 1997). E acresce o problema de, em larga medida, os próprios romanos terem abordado as sociedades que encontraram na expansão do seu Império (especialmente para Ocidente e para Norte, onde encontraram organizações diferentes das monarquias helenísticas e que foram por isso consideradas mais primitivas) sob preconceitos muito idênticos (IsAAC 2004: 55-168).

Aqueles que os romanos identificaram como Aranditani, conclua-se então, eram, em suma, um conjunto de comunidades que tendiam a agregar-se em povoados nucleados (mas substancialmente desprovidos de investimento monumental, à excepção da poliorcética), dispersos num território onde estaria ainda presente a marca de um padrão de povoamento mais difuso, que por vezes se designa por "sistema palacial" (CORREIA 2007).

Esta designação é por vezes, talvez justamente, recusada com vigor. O termo antigo que melhor se aplica a edifícios como o de Fernão Vaz é a palavra grega anaktoron (de anax - "rei"; BENVENISTE 1969: 23-26), que designa um edifício reunindo em si funções residenciais, económicas e cultuais (CASEVITZ 1984). Alguns arqueólogos preferem usar o latim regia (de rex), mas o conhecimento mais pormenorizado da evolução histórica e do papel político da regia por excelência, a da própria Roma, torna esta designação tão ideologicamente carregada quanto a de "palácio" (Almagro 1993). Naturalmente, não sabemos 
qual o termo porque estes edifícios foram designados pelos seus construtores e habitantes.

O que se sabe, e se pode demonstrar é que, entre os séc.s VIII e V a.C. estes edifícios e os restantes fenómenos arqueológicos associados (designadamente as necrópoles e a epigrafia funerária) desenvolveram no vale do Mira um padrão de ocupação do espaço que sobreviveu no registo arqueológico melhor que nenhum outro, desde finais do $\mathrm{II}^{\circ}$ mil a.C. (Correia 1993; Vilhena 2008) até aos alvores da Idade Moderna. Podemos portanto supor que, em datas mais próximas da sua efectiva implantação no território, essa marca na paisagem fosse ainda mais visível e, pode propor-se sem grande esforço de imaginação, que estivesse ainda mais ligada a narrativas históricas e/ou míticas que a explicavam. No processo iterativo e redundante de informação histórica e/ou narrativa mítica e de criação da identidade própria (étnica) das comunidades, esse padrão dual de povoamento teve portanto, necessariamente, de desempenhar um papel de relevo (cf. Fulminante 2012; OsBorne 2012).

Por contraste, o uso diferenciado da epigrafia do sudoeste no Algarve, que não é seguro que tenha acontecido num padrão de povoamento dual do mesmo género, terá deixado uma marca menos potente, pois sabemos que, por diversas razões, nem todas bem conhecidas, o povoamento nucleado ganhou um relevo e uma importância muito maior (CORREIA 1997: 57; id. 2004).

Portanto, se existem evidências muito claras que as identidades de Cilibitani e Balsenses são conceitos alógenos, impostos pelos romanos a agregados de comunidades até aí dotadas de personalidade própria e bem distinta entre si, por maioria de razão se deve supor que o mesmo se passa com os Aranditani. Aliás, se alguma evidência existe é a de que, mesmo em período romano, a identidade comunitária se reconhecia a uma escala menor, como parece indicar o Coilicus de Torre Vã (ENCARNAÇÃo 1984: 202, nº 139), que é claramente uma identificação gentilitária do tipo 2 de M. Faust (1979: 441-444), eventualmente relacionado com a toponomástica (de onde pode derivar o moderno Colos?).

\section{Povoamento e território}

Neste âmbito geral, as evoluções particulares dos povoados nucleados, quando um dia, idealmente, se conhecerem todas (ou mais 
realisticamente, quando se dispuser de uma amostragem suficiente, ao contrário da situação actual, onde só dispomos de escavações de qualidade em Fernão Vaz e nas Mesas do Castelinho), aparecerão como elementos de um padrão, seguramente mais complexo do que aquele que hoje podemos traçar, mas cujo elemento central não poderá deixar de ser o mesmo: um episódio marcante na ocupação do território, de características específicas, que o marca "intemporalmente".

Talvez seja esse o fenómeno por detrás de uma inevitável perplexidade suscitada pela bibliografia manejada: a de que, com a "experiência urbana e administrativa falhada" de Arandis, o "urbanismo falhado" em Mesas do Castelinho e o desaparecimento do concelho de Marachique em época medieval, a região que abordamos seja tão excepcionalmente rica em urbanizações abortadas, como em nenhum outro fenómeno histórico-arqueológico ou territorial.

Pelo contrário, desde a Pré-história recente, um território sempre sistematicamente ocupado (VILHENA 2009), assiste a épocas de cristalização de povoamento nucleado em função de condicionalismos históricos concretos, ainda que em grande medida indeterminados (v.g. no Bronze Final: VilHENA e GonÇALVES 2012) segundo modelos comportamentais globais que se podem modelizar (CORREIA 2000: 421-422), tal como acontece com o povoado de Mesas do Castelinho no séc. V a.C., para que se pode apelar ao exemplo do sinoecismo aristocrático ocorrido na Plaza de Armas de Puente Tablas (Ruíz 1995), modelo que, todavia, tem tanta (ou tão pouca) "necessidade histórica" de sobrevivência, quanto qualquer outro. Marachique, por seu lado, é vítima natural da reorganização do território pela monarquia portuguesa na segunda metade do séc. XIII, e um dos seus últimos actos conhecidos, a doação a D. Estêvão Anes, em 1260, de uma herdade compreendendo mais de metade do seu território (VIANA 1961: 72-79), pode ser interpretado ainda como uma derradeira manifestação da resiliência do elemento não-nucleado no padrão dual de povoamento, então já velho de dois milénios.

O problema da ocupação imperial romana no vale do Mira é, pelo contrário, o da manutenção, dir-se-ia in naturalibus (ISAAC 2004: 196-207) de uma vasta zona, que foi ocupada mas que não adoptou, num contexto forte de estruturação política, nenhuma das características essenciais dessa estruturação, mesmo em zonas administrativamente ordenadas, como parece ter acontecido com parte do território de Myrtillis (Alarcão 1985: 101-102), o que é distinto da situação 
ocorrida, por exemplo, na região montanhosa à volta da Serra da Estrela (AlarCão 1990: 27-28) onde tal ordenação administrativa não terá estado nunca presente. Parece, pois, indispensável tentar abordar as razões desse fenómeno.

Há uma perspectiva, empiricamente sistémica, que proporá que a área considerada, a bacia do Mira e do Alto Sado, é uma zona de "baixa energia", inadequada ao desenvolvimento urbano, mas esta é uma perspectiva rudimentar, que necessita de elaboração a vários níveis.

Delimitado o território, os referidos $3000 \mathrm{~km} 2$, a eles corresponde claramente uma unidade geomorfológica de características muito particulares que, sem uma definição "dura", para além da presença dominante na geomorfologia de um sistema de cristas de intersecção arredondadas (Feio 1951, mapa extratexto), explica, numa dualidade território/ambiente (Assunto 2011), um elemento essencial da realidade com que lidamos actualmente e com a qual, porventura, se lidou em períodos antigos sem modificações radicais. A crux do problema reside na tendência humboldtiana de entender o binómio território/ ambiente como determinante do sentido da acção do elemento agencial da ocupação humana; nesta circunstância parece adequado insistir na inexistência de qualquer Stimmung (cf. HenNRICH 2012) que tenha condenado as populações da bacia do Mira e Alto Sado a uma baixa densidade populacional e à ausência de nucleação até aos meados do séc. XIII d.C.

Pelo contrário, a questão essencial no entendimento das estruturas de povoamento da área considerada no período que interessa (segunda metade do segundo milénio a.C., primeira metade do primeiro milénio d.C.), tem a ver com o carácter verdadeiramente agencial ou apenas perceptivo das comunidades humanas e com a sua acção e/ou a sua abstenção accional (BouRDIEU 2011: 108-24).

Neste ponto, a noção de um "limiar ecológico", ou o seu reverso de "potencial humano" (noção afim ao Stimmung de A. v. HumboldT e grata à demografia antiga tradicional, na esteira de J. BeLoch [1886] a A. Momigliano [1994]; cf. Cornell 1999: 245-247 especialmente n. 25) recorre na discussão e é inevitável recorrer a outros dados, anacrónicos mas relevantes, sobre a mesma área.

Entre 1801 e 1960, um período temporal equivalente ao que medeia entre a batalha de Munda e o final do reinado de Trajano, a área que nos interessa quadruplicou de volume populacional (contra FeIo 1983, 30-34), depois de um período (1750-1800) em que parece 
existir já este movimento (MARCADÉ 1971: 42-43), mas não ter ganho ainda o desenvolvimento exponencial do séc. XIX. É ociosa e metafísica (no sentido popperiano de "não-científica". Cf. POPPER 2003: 264-74) a comparação entre as potencialidades de desenvolvimento oferecidas ao nascente Império Romano e as oferecidas à tardo-monarquia e à primeira república portuguesas no mesmo território. Concluir-se-á apenas dizendo que não terá sido por simples impossibilidade ecológica que uma região, historicamente capaz de receber todos os influxos que the foram proporcionados, não os acolheu nesse momento da Antiguidade. Dito de outra forma, as leis de Liebig e de Shelford e os conceitos delas decorrentes (ODum 1988: 167-219) não se aplicam nesta problemática, pois os limites só foram atingidos, se tal foi o caso, no final do séc. XX.

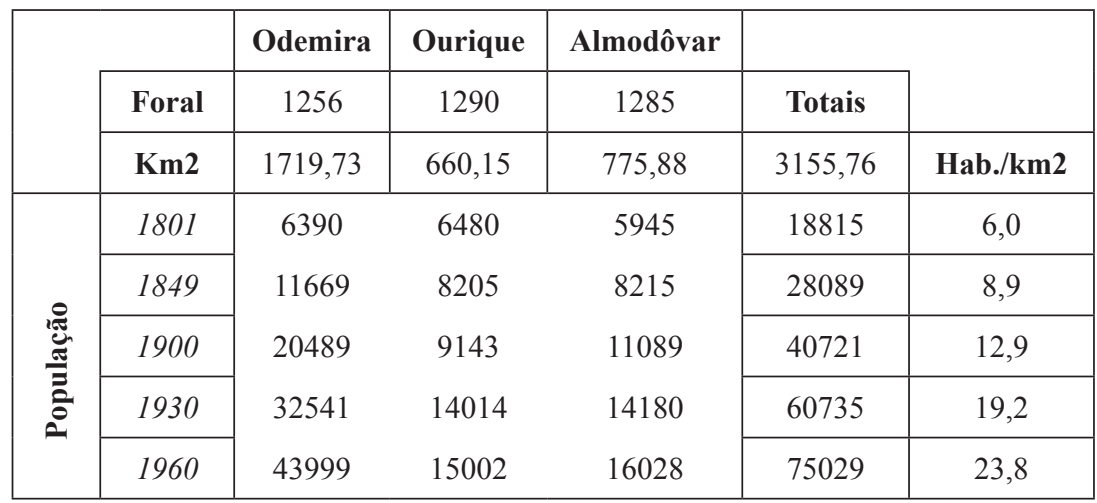

QUADRo 1 - A bacia do Mira na organização portuguesa

(todos os dados segundo pt.wikipedia.org em 11/5/2013)

O que reconduz o problema à questão da paisagem, como terceiro elemento da equação que se se inicia com o território e o ambiente (Assunto, loc. cit.) e obriga a recorrer, na medida em que se aceite a intervenção do elemento humano no trinómio, seja na posição de agente seja no simples acto de percepção, ao habitus enquanto forma de gestão de um capital simbólico (BouRdieu 1980: 195-197), enquanto elemento de "transdução" entre a perceção das materialidades (paisagísticas) e as intervenções cinestésicas que indivíduos e sociedades operam correspondentemente a elas, segundo o conceito de T. Ingold (2013: 102-108) que refina o tradicional conceito do Homem operando 
"sobre" a paisagem; o resultado vai no sentido de criar heterarquias territoriais (CRUMLeY 2003; cf. GonZALEZ 2012 e Vives 2012 para outras utilizações do conceito na Península em datas pré-romanas), que no vale do Mira se afirmaram de uma forma sem paralelo no Ocidente imperial, tanto quanto hoje é aparente.

A ocupação de época imperial na bacia do Mira mostra, em suma, uma afirmação de identidade colectiva feita, não através de uma reflexão passiva do comportamento normativo de um grupo discreto de pessoas, mas enquanto objetificação da diferença, com raízes no percurso histórico das comunidades, tal como elas o perceberam (Cf. Jones 1997: 92-100; StOdDART e NeIL 2012).

\section{Questões conclusivas}

A questão significativa na bacia do Mira e do Alto Sado, entre os séc.s II a.C. e V d.C. é a da identificação de uma agência por abstenção, irredutível a um fenómeno de despovoamento por preferência relativamente a áreas limítrofes mais vantajosas. $\mathrm{O}$ argumento que rejeitamos, e que de certa forma está subjacente a alguma argumentação esgrimida a propósito de Arandis, é a de que a mineração de Vipasca e a produção de garum e suas ânforas do Algarve, despovoaram a bacia do Mira dos trabalhadores necessários a estas produções de alto rendimento, reduzindo esse hinterland à sua "inevitável" menoridade económica e política (contra CORREIA 2002: 15 ou, em menor medida, AlARCÃo 1985: 101-102, a propósito do território de Myrtillis). Esta narrativa não é, em melhor exame, credível, sobretudo em sociedades que são, primordial e necessariamente, agrícolas, apesar dos aspetos respeitáveis da teoria académica tradicionalmente aceite (CURCHIN 2004: 124-126).

Não há presentemente razões para pensar que a atividade mineira nas zonas privilegiadas pela natureza na Península tenha acarretado uma diminuição dos volumes populacionais alhures, que se refletiria nessas zonas como um fenómeno assinalável de crescimento populacional pela imigração (SÁNCHEZ-Palencia et al. 2006: 281-282; CHIC 2007: 18-19; AMOREs et al. 2014: 231-232), enquanto localmente, nos vales do Mira e Sado, uma atividade mineira de pequena monta (Vilhena e GrANGÉ 2011: 99-103) terá coexistido com os efeitos de imigração provocados pelas explorações de Vipasca, que terão captado gentes de outras regiões (Dias 1979: 218-226; GoMes e GoMes 1984: 48-53). O 
caso está menos estudado (se de todo) no que diz respeito aos efeitos do incremento económico das regiões costeiras produtoras de garum (MANTAS 1996: 343-370; EtiENne e MAYet 2002: 224-226), mas tão pouco existem aí evidências significativas de imigrações importantes.

A exclusão das sociedades da bacia do Mira relativamente às formas de uma expressão urbana e erudita no período romano é uma escolha, de sentido diverso, mas de intensidade tão grande, quanto a efetiva romanização das restantes áreas do sudoeste peninsular (cujas escolhas particulares estão ainda, substancialmente, por determinar e descrever). O vector essencial do problema terá, porventura, estado mais vinculado às opções da elite local, na sua qualidade de principais manipuladores do capital simbólico através da qual se faz o auto-reconhecimento da comunidade como ethnos (CORREIA 2000b), nomeadamente a pontuação da paisagem com os vestígios monumentais das linhagens, consistindo nas necrópoles e na epigrafia que, histórica ou mitologicamente, as explica, do que em qualquer outro dos vectores eventualmente carreados para a discussão.

A aparente não-ocupação do vale do Mira e do Alto Sado no período imperial tem, por tudo o que aqui se expôs, de deixar de ser interpretado como uma elipse (de conhecimento, de investigação - de "ignorância e esquecimento", para retomar o tema do colóquio que originou este texto); ou como um resíduo intersticial de um padrão coerente mais vasto: o padrão, onde existiu, tendeu a não deixar resíduos, pese embora a sua infinita capacidade de adaptação às distintas e mutáveis condições de base, sobretudo nas zonas onde, na mitologia científica, esse processo ocorre de forma mais pura.

Se, como sustentou P. BRUNT (1990: 268), "o governo [romano] mais não podia fazer do que encorajar um processo que, sem sistema público de educação, não tinha meios para impor. Os provinciais romanizaram-se a si próprios" (meu sublinhado), encontramos na bacia do Mira aqueles que não.

O vale do Mira é uma região sui generis, onde a afirmação da personalidade cultural das populações escolheu formas distintas daquelas que conhecemos noutras regiões. Se toda a reconstituição histórica é uma narrativa, então a investigação da presença romana na bacia do Mira pelos Romanos convoca uma outra, de Agustina Bessa Luís (2003: 366): ... as coisas ficavam como estavam, aconselhadas e protegidas por fantasias, sonhos, crueldades finas como um cabelo. Camila disse: 


\section{REFERÊNCIAS}

AlARCÃo, Jorge de (1985) - Sobre a romanização do Alentejo e Algarve. A propósito de uma obra de José d'Encarnação. Arqueologia 11, p. 99-111.

Alarcão, Jorge de (1988) - Roman Portugal (Warminster, Aris \& Phillips Ltd).

Alarcão, Jorge de (1990) - Identificação das cidades da Lusitânia portuguesa e dos seus territórios. In Les villes de la Lusitanie Romaine. Hiérarchies et territoires (Paris, Ed. CNRS, Collection de la Maison des Pays Ibériques 42), p. 21-34.

AlARCÃo, Jorge de (1992) - Etnogeografia da fachada atlântica ocidental da Península Ibérica. In Almagro-Gorbea, M. e Ruiz Zapatero, G. (eds.) Paleoetnologia de la Península Ibérica (Madrid, Un. Complutense, Complutum 2-3), p. 340-345.

AlarCÃo, Jorge de (2010) - A costa portuguesa em Artemidoro. Revista Portuguesa de Arqueologia 13, p. 107-123.

Almagro-Gorbea, Martin (1993) - Palacio y organización social en la Península Ibérica. In Untermann, J. e VILlaR, F. (eds.) Lengua y cultura en la Hispania Prerromana. Actas del V Coloquio sobre lenguas y culturas prerromanas de la Peninsula Ibérica (Salamanca, Ediciones, Un., Acta Salmanticensia - Estudios Filologicos 251), p. 21-48.

Amores, Fernando; García Vargas, Enrique; Garrido González, Pablo; Hunt Ortiz, Mark A.; Vázquez Paz, Jacobo E RodríGuez Mellado, Jesús (2014) - Los Paisajes Históricos del Valle del Guadiamar (Sevilla): La Minería y la metalurgia en el extremo oriental del cinturón ibérico de piritas. In ARBOLEDAS Martínez, Luis; Contreras Cortés Francisco E Moreno Onorato, Auxilio (Eds) Los Paisajes Mineros de la Península Ibérica: la minería metálica en la Antigüedad (Granada, Universidad, Cuadernos De Prehistoria Y Arqueología de la Universidad de Granada 24), p. 203-237.

Arruda, Ana Margarida; Guerra, Amílcar e Fabião, Carlos (1995) - O que é a II ${ }^{\mathrm{a}}$ Idade do Ferro no Sul de Portugal. In Actas do $1^{\circ}$ Congresso de Arqueologia peninsular, vol. VI (Porto. SPAE, Trabalhos de Antropologia e Etnologia 35, 2), p. 237-257.

Assunto, Rosario (2011) - Paisagem - Ambiente - Território. In Serrão, A. V. (coord.) Filosofia da paisagem. Uma Antologia (Lisboa, Centro de Filosofia da Un.), p. 126-130.

Beirão, Caetano de Melo; Silva, Carlos Tavares da; SoARes, Joaquina; Gomes, Mário Varela e Gomes, Rosa Varela (1985) - Depósito votivo da II Idade do Ferro de Garvão. Notícia da primeira campanha de escavações. O Arqueólogo Português s. IV 3, p. 45-135.

Beloch, K. J. (1886) - Die Bevölkerung der griechish-römischen Welt (Leipzig, vg. Von Dunker \& Humblot, Historische Beiträge zur Bevolkërungslehre I).

Benveniste, Emile (1969) - Le vocabulaire des institutions indo-europeénes 2. Pouvoir, droit, religion (Paris, Les editions de minuit).

Bernardes, João Pedro (2006) - A propósito da localização de Arani/Arandis. Conimbriga 45, p. 153-164.

Conimbriga, 54 (2015) 157-178 
172 Virgílio Hipólito CoRReIA Observações sobre a ocupação de época romana...

Blot, Maria Luísa B. H. Pinheiro (2003) - Os portos na origem dos centros urbanos (Lisboa, IPA, Trabalhos de Arqueologia 28).

Bourdieu, Pierre (1980) - Le sens pratique (Paris. Les editions de minuit).

Bourdieu, Pierre (2011) - O poder simbólico (Lisboa, Edições 70).

Brunt, P. A. (1990) - Roman imperial themes (Oxford, Clarendon Press).

Burillo Mozota, Francisco (1998) - Los celtíberos. Etnias y estados (Barcelona, Crítica).

Casevitz, M. (1984) - Temples et sanctuaires: ce qu'apprend l'étude lexicologique. In Roux, G. (dir.) Temples et sanctuaires (Lyon, Maison de l'Orient mediterranéen, Travaux de la Maison de l'Orient 7), p. 81-96.

Cerrillo Martín de Cáceres, Enrique; Fernández Corrales, José Maria e Herrera GARCIA DE LA SANTA, Gregório (1990) - Ciudades, territórios y vías de comunicación en la Lusitânia meridional española. In Les villes de la Lusitanie Romaine. Hiérarchies et territoires (Paris, Ed. CNRS, Collection de la Maison des Pays Ibériques 42), p. 51-72.

ChIC García, Genaro (2007) - La zona minera del suroeste de hispania en época julio-claudia. In Pérez Macías, Juan Aurelio e Delgado Domínguez, Aquilino (eds.) Las minas de Riotinto en época Julio-Claudia (Huelva, Servicio de Publicaciones de la Universidad, Colectanea 107), p. 11-36.

Cornell, T. J. (1995) - Los orígenes de Roma c. 1000-264 a.C. (Barcelona, Crítica/ Arqueología).

Correia, Susana H. (ed.) (1985) - Ponte de Vila Nova de Milfontes. Informação Arqueológica 5 (1982/1983), p. 9.

Correia, Virgílio Hipólito (1993) - As necrópoles da Idade do Ferro do Sul de Portugal: arquitectura e rituais. In Actas do $1^{\circ}$ Congresso de Arqueologia Peninsular, Vol. II (Porto, SPAE, Trabalhos de Antropologia e Etnologia 33, 3-4), p. 351-375.

Correia, Virgílio Hipólito (1995) - The Iron Age in South and Central Portugal and the emergence of urban centres. In Cunliffe, B. e KeaY, S. (eds.) Social Complexity and the development of towns in Iberia. From the Copper Age to the second century AD (Oxford, Un. Press, Proceedings of the British Academy 86), p. 237-262.

Correia, Virgílio Hipólito (1996) - O sítio arqueológico de Garvão e o seu depósito ritual. In Alarcão, J. (Coord.) De Ulisses a Viriato (Lisboa, Inst. Port. de Museus), p. 101-106.

Correia, Virgílio Hipólito (1997) - Um modelo historiográfico para a Idade do Ferro do Sul de Portugal e a sua arqueologia. Trabalhos de Antropologia e Etnologia 37, 3-4, p. 41-85.

CORREIA, Virgílio Hipólito (2000a) - Modelos de interpretação e arqueologia proto-histórica. In Jorge, V. O. (coord.) Actas do $3^{\circ}$ Congresso de Arqueologia peninsular, vol. 5. Proto-história da Península Ibérica (Porto, ADECAP), p. 413-428.

Correia, Virgílio Hipólito (2000b) - Algumas considerações sobre os centros de poder na Proto-história do Sul de Portugal. In Actas do Congresso de Proto-história

Conimbriga, 54 (2015) 157-178 
Europeia (Guimarães, Sociedade Martins Sarmento, Revista de Guimarães volume especial) vol. 2, p. 699-714.

CORreia, Virgílio Hipólito (2002) - Cola. Circuito Arqueológico (Lisboa, IPPAR, Roteiros da Arqueologia Portuguesa 8).

Correia, Virgílio Hipólito (2004) - Moeda, epigrafia e identidade cultural no ocidente peninsular pré-romano. In Chaves Tristán, F. e García Fernandez, F. J. (eds.) Moneta qua scripta. La moneda como soporte de escritura (Sevilha, CSIC, Anejos de Archivo Español de Arqueologia 33), p. 267-290.

Correia, Virgílio Hipólito (2007) - Fernão Vaz. Um caso de estudo da paisagem rural do Sudoeste no Período Orientalizante. In Rodríguez Díaz, A. e Pavón Soldevilla, I., (eds.) Arqueologia de la tierra. Paisajes rurales de la proto-história peninsular (Cáceres, Un. Extremadura, VI Cursos de Verano Internacionales de la Un. Ext.), p. 181-194.

Correia, Virgílio Hipólito (2009a) - Espaços urbanos e modelos domésticos na proto-história da fachada atlântica. In Bellarte, M. C. (ed.) L'espai domèstic i l'organització de la societat a la protohistòria de la Mediterrània ocidental (Ier mil. lenni aC), (Barcelona, ICAC, Arqueomediterrània 11), p. 271-277.

CORReIA, Virgílio Hipólito (2009b) - A escrita do sudoeste: uma visão retrospectiva e prospectiva. In Acta Palaeohispanica X. Actas do X Colóquio sobre línguas e culturas Paleo-hispânicas (Saragoça, Inst. 'Fernando el Católico', Palaeohispanica 9), p. 309-321.

Corriente, F. (19843) - Gramática árabe (Madrid, Instituto Hispano-Árabe de Cultura).

Crumley, C. (2003) - Alternative forms of social order. In Scarborough, V.; Valdez, F. e Dunning, N. (eds.) Heterarchy, political economy and the ancient Maya: the Three Rivers region on the east central Yucatan peninsula (Tucson Az., The University of Arizona Press), p. 345-360.

Curchin, Leonard A. (1991) - Roman Spain (Londres Routledge).

Curchin, Leonard A. (2004) - The Romanization of Central Spain (Londres, Routledge).

Dias, Maria Manuela Alves (1979) - A propósito da inscrição B-143 do Museu Regional de Beja”. Conimbriga 18, p. 203-226.

EnCARnação, José d' (1984) - Inscrições Romanas do Conventus Pacensis (Coimbra, Instituto de Arqueologia).

ETIENNE, Robert (1990) - Le culte impérial, vecteur de la hiérarchisation urbaine. In Les villes de la Lusitanie Romaine. Hiérarchies et territoires (Paris, Ed. CNRS, Collection de la Maison des Pays Ibériques 42), p. 215-231.

ETIEnNe, Robert e Mayet, Françoise (2002) - Salaisons et sauces de poisson hispaniques (Paris, De Boccard, Trois clés pour l'économie de l'Hispanie romaine II).

FABiÃo, Carlos e Guerra, Amílcar (2010) - Mesas do Castelinho (Almodôvar): a case of a failed Roman town in Southern Lusitania. In Corsi, C. e Vermeulen, F. (eds.) Changing landscapes. The impact of Roman towns in the Western Mediterranean (Évora, CIDEHUS), p. 325-346.

Conimbriga, 54 (2015) 157-178 
174 Virgílio Hipólito CoRReia Observações sobre a ocupação de época romana...

FAust, Manfred (1979) - Tradicion lingüistica y estructura social. El caso de las gentilitates. In Tovar, A.; Faust, M. Fischer, F. e Koch, M. (eds.) Actas del II coloquio sobre lenguas y culturas prerromanas de la Peninsula Ibérica (Salamanca, Ed. Universidad), p. 435-452.

FeIo, Mariano (1951) - A evolução do relevo do Baixo Alentejo e Algarve. Comunicações dos Serviços Geológicos de Portugal 32, 2, p. 303-477.

FeIo, Mariano (1983) - Le Bas Alentejo et l'Algarve (Évora, INIC, Reimpressão do Livret-Guide du Congrés International de Géographie de Lisbonne, Lisboa, 1949)

[Fernandes, Raúl M. Rosado, ed.] Resende, André de, [1996] - As antiguidades da Lusitânia (Lisboa, F. C. Gulbenkian).

Fulminante, Francesca (2012) - Ethnicity, identity and state formation in the Latin landscape. Problems and approaches. In CifAni, G. e Stoddart, S. (eds.) Landscape, ethnicity and identity in the archaic Mediterranean area (Oxford, Oxbow Books), p. 89-107.

Gomes, Rosa Varela e Gomes, Mário Varela (1984) - Uma estela epigrafada da Herdade dos Franciscos (Garvão). Conimbriga 23, p. 43-54.

GonZalez Ruibal, Alfredo (2012) - The politics of identity: ethnicity and the economy of power in Iron Age north-west Iberia”. In Cifani, G. e Stoddart, S. (eds.) Landscape, ethnicity and identity in the archaic Mediterranean area (Oxford, Oxbow Books), p. 245-266.

Guerra, Amílcar (1995) - Plínio-o-Velho e a Lusitânia (Lisboa, Ed. Colibri, Arqueologia \& História Antiga 1).

Guerra, Amílcar e Fabĩ̃o, Carlos (2010) - Mesas do Castelinho (Almodôvar): um exemplo de urbanismo falhado no sul da Lusitânia. In Gorges, J.-G. e NoGales Basarrate, T. (eds.) Naissance de la Lusitanie Romaine (I av - I ap. J.C.) (Toulouse/Mérida, VII Table Ronde Internationale sur la Lusitanie Romaine), p. $459-488$.

HennRICH, Dirk-Michael (2012) - Paisagem e identidade europeia. In Serrão, A. V. (coord.) Filosofia e arquitectura da paisagem. Um manual (Lisboa, Centro de Filosofia da Un.), p. 131-142.

HodDER, Ian R. (1972) - Locational models and the study of Romano-British settlement”. In Clarke, D. L. (ed.) Models in archaeology (Londres, Methuen \& Co Ltd), p. 887-910.

Hodder, Ian e Hassall, Mark (1971) - The non-random spacing of Romano-British walled towns". Man 6, p. 391-407.

JONES, Siân (1997) - The archaeology of ethnicity. Constructing identities in the past and present (Londres, Routledge).

IsAAC, Benjamin (2004) - The invention of racism in classical antiquity (Princeton NJ, Un. Press).

Ingold, Tim (2013) - Making. Anthropology, Archaeology, Art and Architecture (Londres, Routledge).

Conimbriga, 54 (2015) 157-178 
VIRGílio HiPÓLITO CORReIA Observações sobre a ocupação de época romana... 175

Lopes, David (Machado, José Pedro [org.]) (1968) - Nomes árabes de terras portuguesas (Lisboa, Sociedade de Língua Portuguesa).

Luís, Agustina Bessa (2003) - Os espaços em branco (Lisboa, Guimarães editores, $O$ princípio da incerteza 3 ).

Mangas, Julio (2014) - Ciudades sin urbe en la Hispania romana. In MARTínez Fernández, Ángel; Ortega Villaro, Begoña; Velasco López, Henar e Zamora Salamanca, Henar (eds.) Ágalma. Ofrenda desde la Filología Clásica a Manuel García Teijeiro (Valladolid, Ed. Universidad), p. 807-830.

Mantas, Vasco Gil (1996) - Comércio marítimo e sociedade nos portos romanos do Tejo e do Sado. In FiLIPE, Graça e RAPoso, Jorge Manuel C. (coords.) Ocupação Romana dos estuários do Tejo e do Sado (Lisboa, C. M. Seixal/Pub. D. Quixote), p. 343-370.

Mantas, Vasco Gil (1997) - As civitates: esboço da geografia política e económica do Algarve romano. In BARATA, M. F. (coord.) Noventa séculos entre a serra e o mar (Lisboa, IPPAR), p. 283-310.

Mantas, Vasco Gil (2012) - As vias romanas da Lusitânia (Mérida, MNAR, Studia Lusitana 7).

MARCADÉ, Jacques (1971) - Une comarque portugaise - Ourique - entre 1750 et 1800 (Paris, Centro Cultural Português, Série Histórica e Literária 6).

Melro, Samuel; Barros, Pedro; Guerra, Amílcar e Fabião, Carlos (2009) - O projecto 'Estela': primeiros resultados e perspectivas. In Acta Palaeohispanica $X$. Actas do X Colóquio sobre línguas e culturas Paleo-hispânicas (Saragoça, Inst. 'Fernando el Católico', Palaeohispanica 9), p. 353-359.

Momigliano, Arnaldo (1994) - Studies on modern scholarship (Berkeley, Un. California Press).

Odum, Eugene P. (1988) - Fundamentos de ecologia (Lisboa, Fund. C. Gulbenkian).

Oleiro, João Manuel Bairrão (1986) - Mosaico Romano. In Alarcão, J. (dir.) História da Arte em Portugal, vol. 1. Do Paleolítico à arte visigótica (Lisboa, Publicações Alfa), p. 111-127.

OliveIRA, Eduardo Pires (1984) - Bibliografia Arqueológica Portuguesa (1935-1964) (Lisboa, IPPC).

Osborne, Robin (2012) - Landscape, ethnicity, and the polis. In CifANI, G. e STODdarT, S. (eds.) Landscape, ethnicity and identity in the archaic Mediterranean area (Oxford, Oxbow Books), p. 24-31.

Ponte, Teresa Ricou Nunes da (2012) - 15 anos de intervenção arqueológica em Garvão. Actas do V Encontro de Arqueologia do Sudoeste Peninsular (Almodôvar, Câmara Municipal), p. 331-346.

POPPER, Karl (2003) - Conjecturas e refutações (Coimbra, Almedina).

Rodríguez Martin, F. Germán (2010) - Reflexiones en torno a la eleccion del solar para la ubicación de Augusta Emérita: diacronía en la vertebracion del território". In Gorges, J.-G. e Nogales Basarrate, T. (eds.) Naissance de la Lusitanie Romaine (I av - I ap. J.C.) (Toulouse/Mérida, VII Table Ronde Internationale sur la Lusitanie Romaine), p. 117-140.

Conimbriga, 54 (2015) 157-178 
176 Virgílio HiPólito CorReia Observações sobre a ocupação de época romana...

RoncaYolo, Marcel (1986) - Cidade. In Região (Lisboa, INCM, Enciclopédia Einaudi 8), p. 396-487.

Ruíz Rodriguez, Arturo (1995) - Plaza de Armas de Puente Tablas. New contributions to the knowledge of Iberian town planning in the seventh to fourth centuries BC. In Cunliffe, B. e KeAY, S. (eds.) Social Complexity and the development of towns in Iberia. From the Copper Age to the second century AD (Oxford, Un. Press, Proceedings of the British Academy 86), p. 89-108.

SÁnchez-Palencia, F. Javier; Orejas, Almudena; Sastre, Inés e Pérez, Luís Carlos (2006) - Las zonas mineras romanas del noroeste peninsular. Infraestructura y organización del territorio. In Actas del III Congreso de las Obras Públicas Romanas (Astorga, Junta de Castilla y León), p. 265-288.

Sousa, Vasco de (1990) - Portugal (Coimbra, Instituto de Arqueologia, Corpus Signorum Imperii Romani).

Stoddart, Simon e NeIL, Skylar (2012) - Endnote: situating ethnicity. In Cifani, G. e StOdDart, S. (eds.) Landscape, ethnicity and identity in the archaic Mediterranean area (Oxford, Oxbow Books), p. 287-293.

SusINI, Giancarlo (1968) (2 ed. anastatica) - Il lapicida romano. Introduzione all'epigrafia latina (Roma, L'Erma di Bretschneider).

Viana, Abel (1961) - Nossa Senhora da Cola. Notas históricas, arqueológicas e etnográficas do Baixo Alentejo (Beja, Minerva Comercial, Separata do Arquivo de Beja vol. XVII, 1960).

VilhenA, Jorge Humberto Guilherme Costa (2006) - O sentido da permanência. As envolventes do Castro da Cola nos $2^{\circ}$ e $1^{\circ}$ milénios a.C. (Lisboa, Faculdade de Letras, Dissertação de Mestrado).

VilheNA, Jorge (2008) - As armas e os barões assinalados? Em torno das necrópoles monumentais do 'Ferro de Ourique"”. In JimÉnez Ávila, J. (ed.) Sidereum Ana I. El río Guadiana en época post-orientalizante (Mérida, CSIC, Anejos de Archivo Español de Arqueologia 46), p. 373-398.

Vilhena, Jorge (2009) - As pedras lisas. Mós e moagem manual entre a Pré-história recente e a Época Moderna (Odemira, Câmara Municipal).

Vilhena, Jorge (2012) - Odemira underground. FO Magazine 5, p. 44-52.

VilhenA, Jorge (2013) - Milfontes: uma história feita em cacos (maravilhas de Portugal). FO Magazine 6, p. 26-29.

VilhenA, Jorge (n. p.) - Acupunctura em Odemira: duzentos anos de Arqueologia no vale do Mira. In Prista, Pedro (ed.) Actas do Colóquio "Ignorância e Esquecimento" (Odemira, Câmara Municipal), no prelo.

Vilhena, Jorge e GonçAlves, Miguel (2012) - 'Muralhas revestidas de cobre'. A problemática de rochas vitrificadas em povoados do Bronze Final de Odemira e Ourique. In Jiménez Ávila, J. (ed.) Sidereum Ana II. El río Guadiana en el Bronce Final (Mérida, CSIC, Anejos de Archivo Español de Arqueologia 57), p. 517-554.

Vilhena, Jorge e Grangé, Mathieu (2011) - Of slags and men. Iron mining and metallurgy in the Mira valley (Southwest Portugal) from Iron Age to the Middle

Conimbriga, 54 (2015) 157-178 
Virgílio HiPÓLITO CORREIA Observações sobre a ocupação de época romana... 177

Ages. In Martins, Carla Maria Braz; Bettencourt, Ana M. S.; Martins, José Inácio F. P. e CARvalho, Jorge (coords.) Povoamento e Exploração dos Recursos Mineiros na Europa Atlântica Ocidental, (Porto, CITCEM/APEQ), p. 83-112.

VILHENA, Jorge e Rodrigues, Joel (2009) - 'O grande fosso': a escavação arqueológica no Cineteatro Camacho Costa e o cerro do Castelo de Odemira na Idade do Ferro tardia. In Actas do $1^{\circ}$ Encontro de História do Alentejo Litoral (Sines, Centro Cultural Emmerico Nunes), p. 204-214.

Vives FerRandiz, Jaime (2012) - Changing identities in a changing landscape: social dynamics of a colonial situation in Early Iron Age south-east Iberia. In CIFANI, G. e Stoddart, S. (eds.) Landscape, ethnicity and identity in the archaic Mediterranean area (Oxford, Oxbow Books), p. 267-286.

Conimbriga, 54 (2015) 157-178 


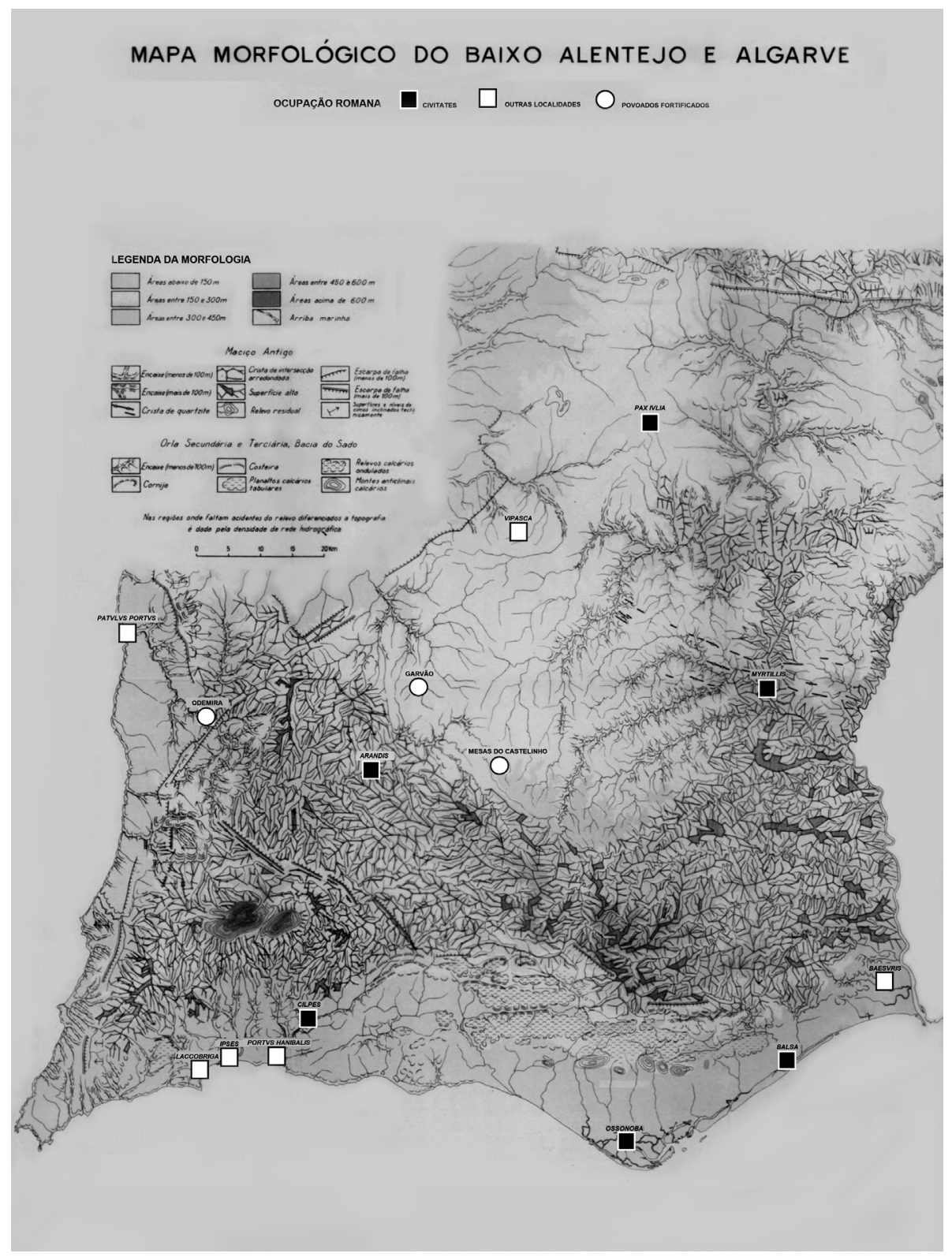

FIg. 1 - A ocupação urbana romana do sul da Lusitânia, sobre a cartografia geomorfológica (segundo Feio 1951, extratexto). 